\title{
Juan María Montijano
}

El 15 de agosto de 2018, el profesor Juan M. ${ }^{a}$ Montijano García falleció de un cáncer con el que había estado conviviendo más de diez años. He de confesar que me resulta muy difícil realizar, solo un mes después, su semblanza personal y profesional sin caer en la emoción sentida, dada la estrecha relación que mantuvimos durante más de veinticuatro años. Quizá un obituario publicado en el Boletín de Arte debiera tener un perfil más académico, más neutro y distanciado, pero confío en que el lector disculpe el que no pueda en estos momentos desbrozar las vivencias personales de lo estrictamente profesional.

Conocí al profesor Juan M. ${ }^{a}$ Montijano en el año 1994. Yo era entonces una alumna de $4 .^{\circ}$ de Historia del Arte y él un joven becario recién llegado a Málaga después de pasar un año en la Real Academia de España en Roma. Lo recuerdo alto, muy delgado y vestido de negro. Nos dio una charla sobre la vida de «pensionado» en Roma. No puedo acordarme de lo que nos contó exactamente aquel día, pero sí persiste en mi memoria el entusiasmo que irradiaba por una ciudad y una cultura que lo conquistaron para siempre.

El profesor Montijano desarrolló su vida académica en la Universidad de Málaga, primero como becario FPI del Ministerio de Educación y Ciencia (1994-1996), después como profesor asociado (1996-2002) y finalmente, desde el año 2002, como profesor titular. Pero su corazón y sus inquietudes intelectuales siempre estuvieron a caballo entre España e Italia. No solo pasaba largas temporadas realizando estancias de investigación en el país vecino; también fueron el Renacimiento y el Barroco italianos los que se convirtieron en el eje central de su reflexión intelectual y de su producción científica.

La estrecha relación del profesor Montijano con Italia constituyó un acontecimiento muy afortunado para el Departamento de Historia del Arte, pues a través de él y de su gestión se fortalecieron los lazos con sus instituciones académicas y culturales, posibilitando, así, el que se abrieran nuevas oportunidades de formación e investigación. Numerosos profesores de la Academia italiana vinieron a Málaga para impartir conferencias y seminarios, lo que fue ocasión para el establecimiento de fuertes vínculos que aún perduran y del que hoy en día disfrutan profesores de nuestro Departamento. Promovió y coordinó la realización de eventos conjuntos para reforzar los intercambios, como los seminarios de doctorado en la Seconda Università degli Studi di Napoli. Se esforzó para que la Real Academia de España en Roma, a la que le unía una especial relación, fuese un espacio abierto para los profesores y estudiantes de la Universidad de Málaga. Promovió y facilitó el que los estudiantes pudieran realizar estancias de formación en Roma y en Nápoles; y fue coordinador de numerosos acuerdos Erasmus firmados con universidades italianas de los que se han beneficiado cientos de estudiantes. En el año 2011, alumbró la feliz idea de diseñar un curso sobre arquitectura que comportaba como novedad el hecho de impartirse in situ en la ciudad de Roma. Con el tiempo, este curso, que se celebraba anualmente, llegaría a convertirse en una cita obligada para los estudiantes de la Universidad de Málaga, que lo esperaban cada año con entusiasmo. Por este curso han pasado no solo la práctica totalidad de los estudiantes de Historia del Arte desde entonces, sino un nutrido grupo de alumnos y alumnas de distintas disciplinas de nuestra Universidad que acudían a la convocatoria simplemente por el gusto -y la curiosidad estética- de descubrir una ciudad de Roma que solo el profesor Montijano era capaz de revelar. Me consta el enorme esfuerzo personal que en los últimos años estos viajes representaron para él, ya afectado por las secuelas de la enfermedad, pero nunca desfalleció en su empeño y mantuvo esta cita -que consideraba ineludiblehasta el final. Me consta también que este curso significó para el profesor Montijano uno de sus mayores logros, una de sus más íntimas satisfacciones, y en mi memoria quedará para siempre su figura, rodeada de estudiantes, ante las fachadas majestuosas del barroco romano. Esta imagen define muy bien su vocación como docente, marcada por la generosidad; siempre buscando experiencias formativas que dejaran una huella indeleble en los futuros historiadores 
del arte, más allá de la adquisición de los conocimientos propiamente disciplinares.

Siempre le gustó la gestión académica. La disfrutaba y la vivía intensamente pese a los sinsabores que por experiencia sé que a veces proporciona. La gestión académica, bien entendida, es un servicio que se realiza a la comunidad universitaria y que requiere no solo esfuerzo sino altas dosis de renuncia profesional. El profesor Montijano así lo asumió y con esa convicción llevó a cabo su tarea durante los años en que fue secretario del Departamento de Historia del Arte (2003-2004), después director (2004-2009), además de miembro del Claustro de la Universidad de Málaga y de la Junta de Facultad de Filosofía y Letras.

En el año 2004 el Consejo de Departamento lo eligió director por unanimidad, cargo que desempeñó hasta la primavera de 2009, cuando una tregua en su enfermedad le llevó a replantearse sus metas profesionales y personales, y a querer vivir más plenamente su vida académica sin las limitaciones que la burocracia de la gestión universitaria impone. Los años del profesor Montijano como director supusieron un punto de inflexión importante para el Departamento de Historia del Arte. Yo tuve la suerte de acompañarle en este periodo como secretaria académica y pude vivir en primera persona esa transformación. Se llevó a cabo una modernización de la gestión de acuerdo a lo requerido por los nuevos tiempos; una transición a las prácticas digitales, tanto en la administración como en la docencia -pese a que a él no le gustaban especialmente-. Se incrementó la proyección internacional, en parte propiciada por él mismo; y el Departamento también experimentó un crecimiento con la incorporación de nuevos miembros y la estabilización de otros. Con todo, también le tocaron vivir tiempos complejos pues fueron los años en los que hubo que iniciar el proceso de adaptación de los estudios universitarios al Espacio Europeo de Educación Superior (EEES). Fiel a su talante, se implicó de una manera intensa y activa en la elaboración del Libro Blanco del Grado de Historia del Arte y en el diseño del nuevo plan de estudios, aunque este se implantara posteriormente. De carácter recio y con las ideas muy claras, pero dotado al mismo tiempo de una admirable capacidad de negociación y habilidad diplomática, fue un incontestable batallador frente a las instancias académicas de todo orden en favor de aquellas cuestiones que consideraba vitales para el crecimiento y el fortalecimiento del Departamento, para la trayectoria profesional de sus miembros y para la formación de los estudiantes de Historia del Arte.

Casualidades (tristes) de la vida, este periodo coincidió con el inicio del deterioro de su salud: un infarto en 2005 y el diagnóstico del cáncer en el verano de 2007 vinieron a ensombrecer estos años que el profesor Montijano ansiaba disfrutar. Pese a todo, lo sobrellevó con una entereza admirable y sin renunciar a sus funciones y obligaciones. En las largas conversaciones que manteníamos sobre el mundo y la vida se mostraba orgulloso de su fortaleza física pero sobre todo de su actitud mental para sobreponerse a las adversidades. Esta actitud le acompañó hasta el final.

Historiador del arte formado en la tradición de la investigación rigurosa y pausada, el análisis escrupuloso de las fuentes y la indagación en archivos; admirador del marco teórico-intelectual de raigambre italiano, del que siempre se confesó deudor, su aportación al conocimiento histórico-artístico se despliega en una abundante bibliografía. El profesor Juan M. ${ }^{a}$ Montijano trabajó sobre numerosos temas a lo largo de toda su vida académica: el patrimonio arquitectónico, en el más amplio sentido del término -no por azar tenía un título de máster en Arquitectura y Patrimonio por el Instituto Andaluz del Patrimonio Histórico (1996-1997)-; el desarrollo urbanístico; la historia de la Academia de España en Roma, de la que da cuenta su imprescindible libro La Academia de España en Roma (1998); y los estudios sobre fuentes, teoría y literatura artística, su otra gran pasión. En este sentido, merece destacar su Vita Nicolai V Sumi Pontificis de Giannozzo Manetti. Edición, traducción y estudio, publicado en un año tan temprano como 1995. Pero sin lugar a dudas su gran legado intelectual se sustancia en dos nombres: Vasari y Borromini, y en una obra magna: la Biblioteca Borrominiana.

A Giorgio Vasari le dedicó su tesis doctoral y estudios posteriores en los que analizó, contextualizó y clarificó el vocabulario artístico elaborado por el artista y teórico aretino. Su contribución, materializada en el libro Giorgio Vasari y la formulación de un vocabulario artístico (2002), es de gran relevancia porque por primera vez en la historiografía española el vocabulario se situaba no solo como una cuestión léxica sino sobre todo y especialmente como un problema epistémico, dando lugar a una refundación de los estudios vasarianos -y, por ende, de la historiografía artística- desde una nueva perspectiva. 
A Francesco Borromini le dedicó su vida entera. Desde el año 1999, en el que se publicó su primera aproximación a Borromini y el Libro della Fabbrica, su bibliografía está salpicada de manera ininterrumpida de estudios sobre el artista y su producción arquitectónica. $Y$ es en este contexto donde se fragua su gran pasión: la iglesia de San Carlo alle Quattro Fontane. Es importante entender que la relación del profesor Juan M. ${ }^{a}$ Montijano con San Carlino no fue la que habitualmente se establece entre investigador y objeto investigado. Por mucho que nos entusiasme nuestro objeto de investigación y nos entreguemos a su estudio con intensidad y convencimiento, siempre permanece una cierta distancia ontológica entre uno y otro (sujeto/objeto). Pero en el caso del profesor Montijano y San Carlino esa distancia se encontraba completamente difuminada. San Carlino era su hogar en Roma y su refugio intelectual. La estrecha relación, familiar, que estableció con la Orden de los Trinitarios hizo de San Carlino su Arcadia feliz. Por eso estoy segura de que también para ellos el hueco que deja el profesor Montijano será irreemplazable.

La primera vez que el profesor Montijano visitó San Carlino, si mi memoria no me falla, fue en el año 1993. Ya tenía en mente una investigación profunda sobre el Libro della Fabbrica. Pero allí se encontró con algo que no esperaba y que marcaría su trayectoria vital: una biblioteca de incalculable valor histórico pero en un estado precario, muy deteriorada, sin catalogar y al borde de la ruina.

Las fotografías que se conservan en el archivo del profesor Montijano sobre el estado de la biblioteca antes de su restauración, ordenación y catalogación dan muestras de la ingente labor que tuvo que llevar a cabo para rescatar del olvido y de la desaparición un patrimonio cultural y bibliográfico imprescindible. La historia de la biblioteca borrominiana roza el género épico: un titánico esfuerzo de casi veinte años, los primeros doce prácticamente solo. La existencia actual de la biblioteca borrominiana, en San Carlino, es el fruto de varios proyectos de investigación coordinados por el profesor Montijano financiados por el Ministerio de Educación y Ciencia; de esfuerzos conjuntos entre la Orden de los Trinitarios, la Universidad de Málaga, la Real Academia de España en Roma y el Ministerio de Asuntos Exteriores de España, que prestaron recursos económicos y apoyo institucional para que, especialmente durante el último periodo, estudiantes de la Universidad de Málaga pudieran colaborar en la catalogación de los fondos. Pero permítanme que diga aquí que la biblioteca borrominiana es fundamentalmente el resultado de una renuncia personal, sobre la que el propio profesor Montijano reflexionaba el día de su inauguración, el 5 de diciembre del año 2012. Ese día, en un acto al que asistieron los embajadores de España en Roma y en el Vaticano, además de otras personalidades de la vida académica española e italiana, el profesor Montijano rememoraba el número de horas y de días que le había robado a su madre -entonces ya fallecida- para llevar a cabo este proyecto; y evocaba todas aquellas navidades que le había escatimado mientras catalogaba y ordenaba la Biblioteca Borrominiana. Lo que define la personalidad del profesor Montijano es que no había amargura o arrepentimiento en esta confesión personal, simplemente la constatación de lo que asumía como una responsabilidad propia de su labor como historiador del arte y como humanista en el más amplio alcance de la palabra. A la entrada de la Biblioteca se encuentra hoy una placa que lo recuerda como promotor y ejecutor de este proyecto, pero el mejor servicio que podemos prestar a su memoria es hacer de ella un instrumento esencial para las actuales y futuras generaciones de investigadores; un enclave de referencia para el conocimiento humanístico.

En junio de 2006, el profesor Juan M. ${ }^{a}$ Montijano recibió del presidente de la República Italiana el título de Cavaliere III clase dell'Ordine della Stella della Solidarietà Italiana, una condecoración en reconocimiento a su aportación al estudio y difusión de la cultura de este país.

Un mes después de su fallecimiento todavía me cuesta trabajo hacerme a la idea de que el profesor Juan M. ${ }^{a}$ Montijano no aparecerá más por la puerta de mi despacho para hablar un rato (de nada y de todo al mismo tiempo); que ya no me lo encontraré de camino al Departamento, cuando a lo lejos lo veía venir con su sombrero negro levantando el brazo efusivamente para saludarme. El vacío va a ser muy difícil de llenar, si es que acaso esto es posible. Me consuela imaginármelo feliz y sosegado, paseando por las calles de su adorada Roma, descansando después de tanto trasiego, y disfrutando de lo que más le apasionaba, el arte en todo su esplendor y magnificencia.

Descansa en paz, mi querido y admirado Monti, y que tu legado perviva en nuestra memoria para siempre.

\section{Nuria Rodríguez Ortega}

